ECONOMICS

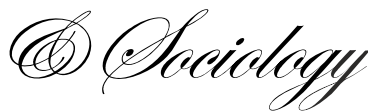

\author{
Anna Kuleshova, \\ Managing Editor of the journal \\ "Public Opinion Monitoring: \\ economic and social changes", \\ VCIOM \\ E-mail:Kuleshovaav@gmail.com
}

Received: May, 2015

1st Revision: October, 2015

Accepted: November, 2015

DOI: $10.14254 / 2071-$

789X.2015/8-4/8

JEL Classification: Z130
Kuleshova, A. (2015), Dillemas of Modern Motherhood (Based on Research in Russia), Economics and Sociology, Vol. 8, No 4, pp. 110-121. DOI: 10.14254/2071789X.2015/8-4/8

\section{DILLEMAS OF MODERN MOTHERHOOD (BASED ON RESEARCH IN RUSSIA)}

\begin{abstract}
This work analyses the main problems of motherhood that are connected to the influence of globalization and its challenges (one the example of Russia). It is based on a ten-year long participants' observation that was conducted by the author via motherhood social networks. An attempt to determine socio-humanitarian definition of "motherhood" is made. We make emphasis on planned maternity as key factor to describe new motherhood scenarios such as Glamour motherhood, problematized motherhood, Professional, Feminist and Cyber motherhood and highlight new motherhood types. This work provides a review of such globalization challenges as Global chains of care and Work-life balance. Author offers an approach to create the index of globalization of motherhood and childhood in order to introduce reference values for researchers. Several problems for future research are listed in the conclusion together with introduction of time structure method as one that looks very perspective and relevant for it.
\end{abstract}

Keywords: motherhood, globalization, family, children, Russia.

\title{
Introduction
}

The concept of globalization is probably one of the most successful frameworks for explaining the dynamic changes within modern societies. Most frequently, the discussion is centred around its positive and negative consequences, and in relation to motherhood in the context of globalization, new forms, dilemmas and possibilities to lose unique cultural identity are discussed.

This article aims at analysing the opportunities and risks that globalization offers to the institute of family through presenting mothers with unfamiliar dilemmas and influencing the nature of new motherhood scenarios. To specify the scale, this work proposes several indicators of the impact of globalization on the private sphere of motherhood in three dimensions: economic, sociotechnical and cultural. We will also analyse several local responses to the challenges of globalization.

This article is based on a ten-year long participants' observation that was held in Moscow and online research through Russia. Being a mother of three children herself, the author was able to actively interact with respondents: interviews in kinder gardens, schools, children's educational centers, etc. Gradually the research that at first was substantially 
qualitative acquired some characteristics of quantitative study. This study covered the analysis of 178 motherhood journals made available for public access; 321 semi-structured interviews, conducted by the author via motherhood social network www.babyblog.ru over a period of time from June 2010 to December 2014. The interviews were conducted with Russian women aged from 19 to 64 years from various regions of Russian Federation; non-probability random sampling was used. The choice of online method was grounded on the fact that during the maternity leave many women find themselves in social isolation and virtual communications become of great importance for them. "Virtual publics and counterpublics provide support, advice and knowledge to women transitioning to motherhood" (Johnson, 2015). Author made her own blog with more than 300 followers and it gave a chance to start discussions on different questions. For example, on the way of celebration of the first Birthday, time structure, consumption templates, etc. As the result of the research, 321 of semistructured interview were made.

Although we understand that this approach can lead to low accuracy in particular indexes due to insufficiently representative sample of respondents, the main goal of the article is to identify the main issues and methods for future research.

We start by an attempt to highlight several indicators of the impact of globalization on the private sphere of motherhood in three dimensions: economic, sociotechnical and cultural. Thorough analyses of all the globalization tendencies is a subject for a number of articles, so we will focus just on some of them.

We should notice that the participants of our observation choose different motherhood strategies, so we summarized them in several "Scenarios of motherhood", based on different aspects of Globalization influence on motherhood. "The practice of mothering furthers identity changes, particularly because women are faced by the realities of motherhood in juxtaposition with their ideals of motherhood" (Laney et al., 2015).

To date, there is no single, universally accepted definition of globalization. For example, P. Sztompka wrote that “...local norms and values, customs and morality, religious beliefs, models of family life, modes of production and consumption seem to be vanishing beneath the pressure of modern western institutions... Current global scale of cultural unification is determined, mainly, by the mass-media, especially television. "Imperialistic means of mass communication" turn our planet into a "big village", inhabitants of which consume the same cultural product". A. S. Panarin (2003) defined globalization as "a process of creating a united interconnected world where nations are not separated from each other by usual protectionist barriers and borders that obstruct their communication and at the same time guard them from chaotic external influence". R. Robertson (1992) viewed it as a "compression" of the world, the increase in interdependency of all its elements accompanied by a more widespread realization of the unity and integrity of the world. He also argued that, on one hand, objective processes of expansion of interaction between different regions of the world exist, and that, on the other hand, these processes are reflected in the minds of people. The Great Russian Encyclopedia offers the following definition: globalization is a modern stage of internationalization of international relations, economic, political and sociocultural processes that are characterized by their high intensity. All concepts that were mentioned are taken into account when we analyse the impact that globalization has on motherhood.

Paradoxically, there is no single sociohumanitarian definition of "motherhood". It used to be connected to biology, the function of childbearing, breastfeeding and caring for an infant; now, given the existence of values of individualism, independence and freedom of women, all these functions can be delegated to other people and government institutions. We agree with the researchers who state that "motherhood in modern culture is a complex and multi-level phenomenon; it is both a routine practice, unique individual experience, and a strict normative institution that regulates this practice, the strategies of speaking and 
presentation of this practice (Nartova, 2013), "in the modern era, a woman can only partially be a mother, both in biological and sociological sense, to the extent never before thought possible" (Isupova, 2011), "the point and meaning of motherhood change depending on whether it is valued by a society or not" (Badinter, 2012). Given the fact that nowadays some children are formally born without a mother (through surrogacy programs), that their birth certificates have a blank space instead of their mother's name, motherhood becomes elusive. We can state unambiguously that a mother is a person responsible for the life and health of a child. That said, the functions of childbearing, childcare and providing security may be delegated to other people, the choice of whom is the responsibility of a mother.

Modern motherhood in Russia is polar. At one pole, there is motherhood not completely connected with a woman's biology (as IVF, surrogacy etc. can be used), and her personality (functions of childcare and upbringing are delegated to nannies, nurseries, grandmothers, schools); it is concentrated around financial support and well-being of a child, and essentialist appeals to the "naturalness" of motherhood are questioned. At the other pole, there is a movement of so-called "natural" and orthodox parents, oriented at child-centrism and the spiritual nature of motherhood. They assist mothers with consciously and peacefully accepting their children; new professions, such as "the art of motherhood instructor", "spiritual obstetrician", "breastfeeding specialist", "perinatal psychologist" etc. were created.

New opportunities to plan one's future appear today, despite the increase in the number of various risks. Nowadays, pregnancy comes as a pleasant surprise for few women; for most, it is well-planned, preceded by medical examinations, psychological preparations and parenting courses.

New biotechnologies and contraception have enabled women to postpone childbirth until they reach a more mature age; in addition, for the first time motherhood has become independent from men. The consequences have been vast. Phenomena of new motherhood and a family that has no place for a man and where a child is born because of a mother's wish (and usually, it is the only child this woman chooses to have) have appeared.

Emancipation has provided women with an opportunity to make a career on par with men, which means that they have become financially independent and able to postpone marriage and childbirth until "a favourable moment" comes. An increase in material wellbeing has led to an increase in material demands.

There are more and more discussions of whether or not a modern woman needs a man in the Internet, forums and media publications. Negative answers are not infrequent. 15 years ago being a single mom was considered immodest; today every third birth is extramarital. A dull term "single mother" was replaced by an optimistic "independent mother", a mother who decided to give birth for herself. Nobody is surprised by this choice; such mothers speak proudly of their status.

A serious argument in favour of becoming a single-mother is the ability to raise children without men, being independent from them both financially and morally. A woman decides for herself when to give birth, how to raise a child and how to live. Here is one of the possible scenarios: a woman lives life to its fullest until she turns 35-38 years old, saves a necessary sum of money for the period she will constantly be with her child, and undergoes the IVF procedure.

Another option is made available by surrogacy. A woman devotes herself to building a career and delegates childbirth to another woman, as she does not want to burden herself with pregnancy, breastfeeding and risk her social status and career. In this model, children become somewhat similar to human commodities: better-off families and couples start seeking women capable of carrying their children. If this approach gains popularity, motherhood may become a regular, well-paid job, spiritual bonds between mothers and children will vanish, and desire to make profits will become more important than common sense. 
All written above applies to the population of large cities. Russia has vast territory and the situation differs from region to region. This work does not cover practices of economically depraved mothers, because in the case of severe shortage of financial resources one should speak about survival strategies, not motherhood.

Emancipation of Russian women, partly influenced the number of children in families and the character of marriages by providing financial independence, equal rights of labour and its remuneration; established a high level of inner and outer mobility; formed the market of social services and so-called "global chains of care". However, in some regions of Russian Federation it has manifested itself through the phenomenon of "economic sterilization", by restricting access to motherhood due to materialistic reasons.

The total Internetization of motherhood has changed the nature of how motherhood experience is formed, expanding the cyberspace and creating an information society. "The online community provides a combination of exoteric advice, information and reassurance, which visitors/ users can discreetly access" (Johnson, 2015).

Because of the technologization of daily life, urban mothers have acquired the ability to replace physical mobility and co-presence with electronic ones (the space is not destroyed, rather it becomes insignificant for many types of interaction (Kharlamov, 2012), including communicating with children and controlling their behaviour); children face new forms of socialization in virtual space. In this context, the development and spreading of biotechnologies is important, as it gives women independence from men in matters of motherhood by providing motherhood and childhood planning and medicalization.

Common cultural space of films and books broadcasts new standards of motherhood and fatherhood, and at the same time, blurs and changes the meaning of these terms. In a globalized world, motherhood ceases to be the only scenario for women: girls receive higher education and put career plans at the same level with, if not above, family plans.

Attitudes towards early childhood have also changed - the priority has shifted from child survival to childcare. The idea that a mother is a person who has to give the child everything, even if it means sacrificing oneself and one's private life, has taken hold. Paradoxically, a mother can delegate all stages of hyper care to other people, accepting responsibility only for financial security of a child and the choice of those who she entrusts her child to. Feminist theories questioning the very existence of maternal instinct (e.g. E. Badinther's theory) are becoming equally popular.

Due to the influence of globalization, routine Russian motherhood is undergoing a qualitative change too - superstitions are forced out of everyday practice, a positive attitude towards competent parenthood, that requires additional education, is formed (motherhood hospitals and commercial centres establish motherhood courses, schools of fatherhood and motherhood).

It is impossible to analyse every tendency mentioned above within one article. Instead, we will focus on some of them and start with outlining what the modern Russian family looks like. We will attempt to define some dilemmas that mothers have to face and outline "mothers' responses" by describing the scenarios of modern motherhood discovered by the author in the course of the research.

\section{Scenarios of motherhood}

\subsection{Glamour motherhood}

Globalization introduced glamour to the daily lives of Russian women. The accent is put on consumption, luxury, sexuality, visual appeal. Some researchers (such as St. Petersburg sociologist D. Ivanov) speak of glam-capitalism, while we find it suitable to 
name one of scenarios of globalized motherhood "glamour motherhood". Such motherhood follows the general trends of the glamour: it needs to be bright, snazzy, lightweight, optimistic and exclusive.

Children of these mothers become supercosumers from the day they are born. Usually, such women decide, while being pregnant, that their motherhood will be unique, beautiful. A lot of shops selling bright and stylish clothes were opened to satisfy this demand; mothers have an opportunity to be examined in a prestigious clinic by a fashionable doctor, to visit motherhood courses, to order childcare products from abroad before the birth of the child. Even before being born, the infant took part in an exclusive studio photo session; they have a portrait taken by a 3-D ultrasound machine; they have listened to the best sonatas by Mozart and Beethoven.

After a baby is born (under supervision by the best specialist of the most expensive clinic), another photo session takes place, now in the motherhood home; a decorated car takes the child home, where an enormous amount of useless things awaits.

After that, the glamour mother runs into some problems, as the child is not exactly that "cutesey" (in terms of glamour motherhood) as expected. Furthermore, it is not completely clear how to make breastfeeding look glamour (users create such topics in blogs or on forums).

Children's rooms in the apartments of this type of mothers look like showcases; new practices of gifting and exchanging toys appear; sometimes they are stashed in storerooms for months in order to be re-introduced to a child; but a glamour mother cannot stop consuming.

A glamour mother has lots of occupations apart from motherhood. She visits fitnesscentres (usually, with her child, to develop them and teach to swim, starting from the age of six months), attends parties, meets friends. If she takes her child to such events, they have to be dressed in trendy clothes; the child is given a tablet computer with games appropriate for children above 8 months old in order to prevent acting up.

Some glamour mothers work while their children are left with nannies (however, even if they do not work, they still get assistance from one or two nannies or relatives).

More and more shops, entertainment clubs, restaurants and educational centers are created, child-oriented advertisements become more common for children's radio stations and urban space. A new type of child-oriented tourism has been created. Companies that operate in the field of entertainment services now offer special programs for children's parties and birthdays. Even Russian museums have become oriented on young consumers, introducing recreational programs for children and even allowing birthdays parties inside their walls (the latter measure was adopted by all museums in the capital, including the Planetarium).

Another specific aspect of glamour motherhood is the fear of hardship. Mothers try to keep the child away from as much things as possible: education must have the form of a game, a situation of success, so that the child's fragile psyche is not traumatized; nannies (who usually accompany children outside) tend to be overcautious, so that the child does not fall and get even an insignificant trauma; when a child takes part in a conflict situation, a mother aggressively intervenes to defend her child.

\subsection{Problematized motherhood}

Problematized motherhood is characterized by the perception of childbirth and upbringing as drudgery. These mothers seem to unconsciously repeat their own childhood scenario, when their mothers had to cope with all the hardness of Soviet everyday life all alone: without washing machines, crockpots, diapers, microwave ovens, vacuum robots, abundance of products in shops. They had to combine the role of a mother with a role of a worker, being torn apart between their home, their jobs, queues in shops and their children. 
Modern women live in a completely different environment, the child is constantly surrounded by educational centres, mobiles, radio-nannies, there are plenty of diapers and toys. However, those mothers will perceive motherhood as a burden, reproducing the same child-caused fatigue they witnessed during their childhood.

They had perceived the discourse "give everything to the child" broadcasted by the media, which was not very popular in Soviet Union. Apart from trying to provide the child with all the goods available in a consumer society, they also try to provide flawless care for the child, devote themselves to upbringing and well-being of the child (denying themselves private life), to flawless care, breastfeeding, permanent co-presence. This model of hypercare renders motherhood unbearable. In fact, we see how the theorem by a sociologist from Chicago school W. Thomas manifests itself: if men define situations as real, they are real in their consequences.

The topic of how bothersome and costly it is to raise a child for their parents is discussed so widely, that a phenomenon of unjudged rejection of motherhood appeared as a response. According to a research by FOM $(2008)^{1}$, only $27 \%$ of respondents stated that they condemn those who do not desire to have children, while $60 \%$ state that they do not judge them at all. In other words, a lot (if not the majority) of Russians consider positive attitude towards childlessness understandable, at the very least. The concept of parental care implies creating certain starting conditions for the child, and some respondents describe those unwilling to have children as responsible people concerned with their child's future: "sensible, normal people. In this economy, with such attitude to people - why?"; "when the child has no perspective, that's when they do not want children"; "nobody wants to see their children suffer in poverty"; "those who take their child's future seriously".

Before giving birth, these women are terrified by the burden of motherhood, of which they heard from their mothers, and are afraid of all those obligations imposed on them by the society. Motherhood is like a prison, a long sentence for them. And all the novelties that ease their lives, provide the freedom of communication (via the Internet) and increase the quality of their lives - are not taken into account. In these women's view, motherhood has to be difficult.

\subsection{Feminist motherhood}

Economic growth, conditioned by globalization, has given women the long-awaited independence, evening work conditions and salaries of men and women. But this trend is not to be confused with the situation in the Soviet Union, where a working mother was a central figure of the government's gender policy. Motherhood was announced to be a "social responsibility of a woman to the state, her public responsibility as opposed to a prerevolutionary private responsibility of a wife to her husband" (Baraulina, 2002, p. 370); it was implied that both the "socially useful labour" and the mother's mission (viewed as "natural female designation" and civil duty) are compulsory.

A modern woman frequently chooses to pursue a career not because the government or the society expects that from her, but due to her wish to maintain her independence both from a man and her function as a mother. If one was to read the Internet forums, they would find out that the rhetoric is as follows: "I gave birth to one baby, realized the horrors of constantly being at home, it was much easier in the office, I will never go through this again"; "I do not want to stay at home and become dumb, staying at home with kids melts the brain"; "one should dress up for work; you feel that you are a person there"; "I like not being dependent on anyone, I want to work, and by the way, I have the right of self-realization".

${ }^{1}$ http://bd.fom.ru/report/cat/socium/demo/d082125. 
Cultural globalization has influenced the separation of women from men's world by changing the attitude of Russian women towards motherhood and family. Patriarchal relationships, conditioned by financial dependence and obedience, were replaced by partnership marriages and women's self-dependence. The degrees of emancipation of women and their immersion in working process have increased; cultural level has changed. The disruption of traditional family and motherhood is closely connected to a global intrusion of western culture: feminist rhetoric is successful at conveying the message that a woman must be above her biology, and that marriage does not necessary imply having children. "Feminists refuted the common assumption of motherhood as something innate to women" (Neyer et al., 2011).

Those Russian mothers who are not willing to sacrifice themselves in the name of the child like to quote an interview of Elisabeth Badinter, a feminist ideologist, who claims that maternal instinct does not exist, that it is merely a construct. Apart from that, they employ her ideas in their motherhood practices: "I think that "normal" motherhood is achieved through certain averaging: a mother does what she can for her child, but she has limits. This idea of averaging should be taught to all young parents. But nowadays women are told the exact opposite. They are told that they were created to be perfect mothers, that they are indebted to their children, which is why they should breastfeed on first demand, never be absent for a long time etc. They are urged to recover the lost maternal instinct"'2. Some mothers support feminist ideas, preferring career and self-realization to excessive communication with their children. Some women take an interest in them while being pregnant, which makes it harder for them to accept their child. In some cases, they employ the services of maternity instructors in order to accept their children. Those mothers actively insist on increasing the number of public nurseries and KinderGardens, considering that all the burdens of caring, training and giving education should not completely fall on the mother (Isupova, 2014).

\subsection{Orthodox motherhood}

In order to respond to the spread of feminist theories, a new movement has emerged in Russia. It is called "natural parents movement" (the abbreviation "ЕР" (rus.: "Естественные Родители") is popular in the Russian segment of the Internet) and stands for orthodox parenthood, child centrism, the inclusion of children in the working lives of mothers (a woman is supposed to pursue a career in a profession that does not prevent her from spending time with her children, such as a freelancer, confectioner for private orders, photographer, needlewoman), "returning to roots" when choosing styles and methods of upbringing. The ideology of this movement corresponds to a utopian image of how children were looked after in prehistoric and ancient times. Some tribes that maintain primordial culture and way of life bring their children up in a way that natural parents are supposed to follow. Jean Liedloff, the ideologist of this movement, described it in her book "The Continuum Concept". She had spent two and a half years living with a South American tribe. In this tribe, she says, relationships between adults and children are filled with harmony, which (in her opinion) modern societies lack. She has come to the conclusion that if we treat our children in the same way "that our ancestors have for thousands of years", they will be calm and happy (Liedloff, 2007). This approach to upbringing has several names: in Russia in the 1980's and the 1990's it was called "conscious parenting" or "empathic parenting", "instinctive care", "attachment parenting", "natural parenting", "parenting from the heart" and "organic parenting" in the West. One of the most well-known Russian centres of natural parenting is the Centre of Perinatal Upbringing and Support of breastfeeding "Rojhana". The founder, J. V. Tsaregradskaya, claims that her recommendations are based on traditional Russian

${ }^{2}$ http://zvezda.ru/antrop/2009/04/03/kids.htm 
methods of childcare and upbringing that were passed down from generation to generation by the most experienced mothers. J. V. Tsaregradskaya was taught childcare by her grandmother, a mother of ten children (seven of which were adopted). In large cities, every district has a centre of family culture, which employs the ideas of natural parenting, promotes breastfeeding, provides support in establishing a strong bond with a child and accentuates traditional Russian motifs in leisure: traditional clothes, songs and games. Orthodox parents mostly share the ideals of natural parenting, but their upbringing practices include fear of God, respect for the elder and regular church attendance.

One specific aspect of Russian natural parenting is the rejection of vaccination, protesting against kindergartens and schools (priority is given to home-schooling), natural birth at home, refusal of medicalization, inseparability from a child less than three years old, public breastfeeding. In matters of medical support of pregnancy and early childhood priority is given to herbal therapy. Women look for "their own personal" midwives who give recommendations according to the principles of traditional medicine: "Girls, I would like some advice. My midwife advised me to drink herbal tea with plantain, licorice and flax seeds. She also recommended lady's mantle and raspberry leaves.

Well, I have no problem with lady's mantle, raspberry or flax seed, but I have significant doubts about plantain and licorice. First of all, they are contraindicative for pregnant women. Secondly, I have trouble finding information concerning their positive influence on the body before giving birth. Specifically, when speaking of licorice, people say that it may cause pre-eclampsia. Hm. I am confused. Who has any info on the subject? And corresponding experience concerning the usefulness of specific herbal teas?"

\subsection{Professional motherhood}

In fact, so-called "professional mothers" bring their motherhood through absolute involvement in their educational practices. "Regardless, women who incorporated their children into their constant awareness had more blurred boundaries between the self and the other when the other was her child, and this may partially be what allowed women to view their children as an integral and embedded part of their identities and to incorporate their children into the boundaries of themselves" (Laney et al., 2015).

They consider motherhood to be a sort of business-plan with "material supply", "financial investments", caring and education categories. They provide total control over the health, circle of friends, study and leisure.

Professional mothers differ from others by the competency level on completely different issues that may be related to her child: psychology, education, medicine, culture, ideology, etc.

They have very high requirements to teachers, schools and doctors. These mothers often become opinion leaders in social networks as they can show "reference" children or reference solution of children's issues.

Some researchers believe that these are the mothers who completely took the responsibility for child caring on themselves, removing it from state, which, in turn, easily agreed. The problem is that not all the women have enough competencies and willingness to become professional mothers that causes problems and conflicts.

\subsection{Cyber motherhood}

Virtual world provides mothers with lots of goods: they can make purchases without leaving their home, watch films, and communicate with people who share their interests, have a blog, and find answers to various questions. They can communicate with their children 
while being at work. Or supervise their children through a webcam. Or supervise a nanny that supervises the child (again, through a webcam). Space ceases to be an obstacle for many forms of interaction, including the communication with children. A mother can keep in touch with her child, provide security and supervision without being present.

In an Internetized society a woman is not as dependent from elder relatives in her motherhood experience as she used to be. Motherhood experience, which in Russia was traditionally passed down from generation to generation, now changes its form and contents. A woman now has the ability to choose the type of motherhood experience she finds most convincing, instead of settling for the experience of her mother or mother-in-law. How and where to give birth, what to eat, whether or not to make a caesarean section if one is afraid of pain and whether or not to breastfeed - all this information can be found in the Internet. It provides global experience in all its variety, which increases its value in the eyes of mothers.

Virtual space allows to maintain anonymity while discussing the problems and mistakes of motherhood, something which not all women can afford in the real world due to fear of judgment. The Internet may be described as a neutral territory, where everyone is free to be themselves. That may explain the fact that it is the Internet where mothers share their first experience of motherhood, their worries and joys. "The development of online community discourse between women enables them to determine what is constituted as knowledge in that space and also works to collapse the informational boundaries of institutional monopolies such as medicine" (Johnson, 2015).

Those who do not have a blog (due to various reasons) read diaries, constructing their own vision of maternity on their basis. These blogs come across as extremely trustworthy. According to some estimates, when it comes to questions of health and upbringing, to $70 \%$ of mothers trust these blogs more than they trust their relatives or doctors. It is proven by collateral data. If one was to check site ratings, they would discover that the most popular site in the "Medicine" category is Babylog.ru, devoted to motherhood and childhood.

Unfortunately, there is no reliable data concerning the participation of mothers on social media in Russia, but we argue that it is relatively similar to that in Europe, at least in case of large Russian cities. Specialists from Babycenter.com, an Internet resource devoted to pregnancy and motherhood, in collaboration with researchers from comScore interviewed 1480 mothers. According to this research, $91 \%$ of mothers frequently use these services. Moreover, they expect their friends to lead an active virtual life. 22\% said that if their relatives/friends do not use the social media, they make no impact on the lives of respondents. In other words, once again we witness the situation when virtualization devalues real co-presence.

Motivational pictures that construct a perfect image of motherhood are popular among Russian social media users. They relay a message that children are the source of great joy; that to be a mother means to be very happy; that relationship with a husband is more important than career; young married women are urged to have children. Demotivational pictures that depict the hardships and problems of motherhood are also popular.

On one hand, because of the Internet, communication it provides, the opportunity to share fears and joys, Russian motherhood became more integral, multi-dimensional, less stereotypical; on the other hand, new problems arise because women neglect the opportunity to see a specialist. In 2012, a mother decided against contacting the clinic when her child started coughing and their temperature rose; the child died. The mother spent the last day of her child's life in contact with women from mothers' community, hoping to receive help and advice from them. Unfortunately, this case is not unique.

It is evident that superstitional practices are in decline: 20 years ago mothers did not prepare beforehand to the birth of a child save for the financial preparation, because buying things for the baby before its birth was considered an omen of misfortune. Nowadays fewer 
mothers are afraid of "hexing" their children this way; more mothers buy go-carts and beds for their children.

In fact, we rarely meet "pure form" of these scenarios, we operate with a certain mix, instead. Still we can use them as a scale to build multidimensional index of motherhood strategies.

\section{Challenges of globalization}

Contemporaneity has introduced new conditions and routine practices, also influencing the strategies of motherhood. We observe two crucial factors that qualitatively change motherhood: maternity planning (the opportunity to delegate the function of childbearing) and "global chains of care". "Mothering from afar routinely effects a reconstitution of 'good mothering' to incorporate breadwinning while maintaining a traditional maternal responsibility of nurturing by employing (tele) communications regulary..." (Chavkin, Maher, 2010).

\subsection{Global chains of care}

Women from peripheral regions move to large cities in order to work as nannies and leave their children with relatives (usually, grandmothers). And mothers from large cities leave their children under supervision by nannies in order to have higher income and provide for their children. This process in Russia is similar to that in other countries and is called "global chains of care". This term was introduced by Arlie Hochschild (2000) to describe "a series of personal links between people across the globe based on the paid or unpaid work of caring". Global chains of care start in poor neighbouring countries and come to a more developed country, sometimes going through another country between the two; alternatively, they start in rural areas of a country and move to urban areas of the same country (Yeates, 2005). Increased demand for domestic servants is usually attributed to the combination of sociodemographic and sociocultural factors, as well as labour market specifics. "Global chains of care" play one of the key roles in globalization processes and policies. "Migrant women have come to replace working middle-class women in private households because their caring practices are seen as "mother-like," while they themselves are yearning to be an intensive mother for their children left behind" (Lutz, 2015).

Arlie Hochshild described a situation where western middle-class wives use the cheap labour of immigrant women - they employ them to do household chores, care for the children and the elderly. By doing that, they manage to combine their professional interests with the interests of their families. The researcher argues (and we find it hard to disagree) that global chains of care disrupt emotional bonds between mothers and children both in the West, where mothers spend less time with their children, and in the countries where nannies and babysitters come from - they care for other people's children and rarely see their own. On the $30^{\text {th }}$ of April, 2010, Russian information agency "RIA-Novosti" made a report about nannies and housekeepers in Russia, focusing on the fact that they are in no way protected against the arbitrariness of their employers: they work without a contract, under constant risk of being fired without pay. The Ministry of Health and Social Development and the Ministry of Labour of the Russian Federation state that the status of domestic servants needs to be legalized, while the State Duma argues that the problem of illegal immigration needs to be solved first, and only then the status of nannies of Russian origin will be discussed. According to research by the Ministry of Health and Social Development, up to 20 million of citizens work in private households - that includes nannies and housekeepers. 
"We have a nanny for our newborn, housing provided; she cooks, cleans the house; has a 12, maximum 14-hour working day, one day off per week; we haven't discussed vacation yet. Naturally, meals are at our expense. Her salary is 30 thousand roubles per month. She has no professional education, but her experience of working in our friends' families is extensive" - this is how one Livejournal user speaks of her nannies' rights and obligations. Globalized Russian reality is quite similar to the European one and introduces new dilemmas: material security or living with children?

\subsection{Work-life balance in the context of motherhood}

As seen above, one of the most complex challenges of globalization is a radical change in work-life balance that influences all aspects of life, including motherhood. On one hand women are given an ability to plan their life, based on newly acquired financial and biological independence. But on the other this choice significantly increases emotional and social pressure and leads to serious conflicts in self-realization and social role. One of the main factors that can be used to evaluate the work-life balance is structure of time. In the context of motherhood strategies and scenarios this factor can be used to make comparisons and build clusters.

\section{Conclusions}

New motherhood scenarios appear in Russian society. On one hand, a woman may not be a mother at all, it is her personal choice, which is not subject to discussion or judgement; on the other hand, she may be any mother she wants by making compromises with her baby, career and private life, by using any methods and by choosing any values.

We have provided examples of some of the most outstanding variants of Russian motherhood. Russian women either choose between these more or less formed variants or decide to raise their parental competence and to choose their own way from the variety of cultural forms and models of motherhood.

It is noteworthy that Christian, soviet and secular ideologies lose their positions of moral regulators. This fact requires the mother to monitor her own abilities and the consequences of her decisions.

The analysis of current processes shows that Russian family and motherhood are placed under constant risks, some of which are caused by globalization (biological motherhood is perceived as a social risk). Most researchers believe that we need mechanisms of defence against negative tendencies. But there is an alternative point of view - that globalization will inevitably change the world, the family and perceptions of motherhood and childhood. It is safe to say that up to date, humanity has not developed any mechanism of reproduction other than family. But today we see how this situation changes because of the development of reproductive technologies.

What will Russian families and mothers be like? This is part of a broader question: what values will the majority of population give priority to? Will it be guided by the principles of freedom or Christian values? Will the future family be monogamous (which is common for a Christian civilization) or be harem-like in certain ways (like "parallel families" of today). Will women come to accept Christian humility and their natural designation, or choose the path of feminism, social realization and separation from men? Will women want to spend their lives on personal ambitions and pleasures alone, or agree to childbirth and having families?

The answers to these questions are of great importance for understanding the global processes that take place in Russia right now. The evolution and rapid change of society 
foundations such as motherhood and family under the influence of globalization should be a subject of thorough research.

The author believes that one of the most promising approaches to further research is the time structure analyses. As it can provide objective and detailed information on the motherhood strategies and tendencies. At the same time this approach requires additional observations and methodology improvement.

\section{References}

Badinter, E. (2012), Conflict, UK: Gardners Books.

Baraulina, T. (2002), Moral Motherhood and the Reproduction of Female Experience, In: Search for Sexuality, St. Petersburg, Dmitry Bulanin.

Chavkin, W., Maher, J. M. (2010), The Globalization of Motherhood: Deconstructions and reconstructions of biology and care.

Hochschild, A. R. (2000), Global Care Chains and Emotional Surplus Value, In: On The Edge: Living with Global Capitalism, London: Jonathan Cape.

Isupova, O. (2011), Modernization of Female Motivation to Give Birth: Deconstructing Motherhood, Demoscope, No 453-454, Moscow. URL: http://www.demoscope.ru/weekly/2011/0453/analit03.php.

Isupova, O. (2014), Tyzhemat, URL: http://polit.ru/article/2014/02/01/isoupova/, access: $20 / 08 / 2015$.

Kharlamov, N. (2012), The Space of Mobile World, Fatherland Notes No 5 (50).

Liedloff, J. (1986), The Continuum Concept, Da Capo Press.

Robertson, R. (1992), Globalization: Social Theory and Global Culture, London.

Nartova, N. (2013), Motherhood in Modern Society: Regulation Instead of Variety, InternetJournal "Novaja Europa”, URL: http://neurope.eu/article/2013/02/06/materinstvo_v_sovremennom_obshchestve_normirovanie _vmesto_raznoobraziya, access: 23/08/2015.

Panarin, A. (2007), Globalization, In: Globalistics: the Encyclopedia, Moscow.

Sztompka, P. (2006), The Sociology of Social Change, John Wiley \& Sons.

Yeates, N. (2005), Global care chains: a critical introduction, Global migration perspectives, No. 44, pp. 1-19.

Johnson, S. A. (2015), 'Intimate mothering publics': comparing face-to-face support groups and Internet use for women seeking information and advice in the transition to first-time motherhood, Culture, Health \& Sexuality, 17:2, pp. 237-251, DOI: 10.1080/13691058.2014.968807.

Laney, E. K., M. Elizabeth Lewis Hall, Tamara L. Anderson \& Michele M. Willingham (2015), Becoming a Mother: The Influence of Motherhood on Women's Identity Development, Identity, 15:2, pp. 126-145, DOI: 10.1080/15283488.2015.1023440.

Lutz, H. (2015), Myra's Predicament: Motherhood Dilemmas for Migrant Care Workers, Social Politics, Vol. 22, No 3, 1 September, pp. 341-359.

Neyer, G., Bernardi, L. (2011), Feminist Perspectives on Motherhood and Reproduction, Historical Social Research, Vol. 36(2), pp. 162-176. 